\title{
EL ENFOQUE DE CAPACIDADES PARA EL TRABAJO SOCIAL THE CAPABILITIES APPROACH FOR SOCIAL WORK
}

\author{
Noé Palomeque Iritia \\ Servicios Sociales de Coslada
}

\begin{abstract}
Resumen: Tradicionalmente se ha estudiado y abordado el problema de la exclusión social con indicadores exclusivamente económicos, ofreciendo como alternativa para la superación de la misma prestaciones de provisión de recursos, principalmente de carácter económico, como si la causa de la exclusión dependiera de tener acceso o no a unos ingresos o rentas suficientes. En este sentido se analiza nuestra principal herramienta de lucha contra la exclusión como es la Renta Mínima de Inserción y la contraponemos al concepto de Renta Básica de Ciudadanía.

Por ello se quiere introducir un nuevo modelo de posicionamiento profesional, el denominado enfoque de capacidades, que sitúa en el centro de la intervención a la persona, desde la conciencia de trabajar con sus propias capacidades, para ampliar su esfera de libertad y situarle como protagonista y responsable de su propia vida. El enfoque se articula como un principio normativo básico tendente a garantizar la dignidad de la persona, definiendo las capacidades como aquellos funcionamientos que las personas son capaces de hacer y ser en el marco de una vida humana digna.
\end{abstract}

Palabras clave: Exclusión Social, Enfoque de Capacidades, Dignidad Humana, Opresión Social, Renta Básica

Abstract: The problem of social exclusion has traditionally been approached and analysed purely from an economic perspective, using primarily economic indicators. Social benefits in the form of economic resources are provided as a means to overcome social exclusion, as if the only cause of the exclusion was not having access to sufficient income. This paper examines the main tool used to eradicate exclusion, the guaranteed minimum income benefit and compares it to the concept of the unconditional basic income or citizen's income.

In relation to the foregoing, efforts are being made to introduce a new model of professional positioning, a model known as the capabilities approach. This model places the individual in the centre of the intervention and focuses on the individual's consciousness of working with his or her own capabilities, to expand his or her sphere of freedom, to make each individual more involved and more responsible for his or her own life. The approach is considered a basic normative principle that seeks to ensure the dignity of the person, defining capabilities as the functionings that people are capable of being and doing, in the context of a dignified life.

Key Words: Social Exclusion, Capabilities Approach, Human Dignity, Social Oppression, Basic Income.

\section{Recibido 09/05/2014 | Revisado 25/07/2014 | Aceptado 02/08/2014 | Publicado 30/09/2014 |}

Correspondencia: Noé Palomeque Iritia. Trabajadora Social del Centro de Servicios Sociales de Coslada (Madrid). Concejalía de Servicios Sociales y Mayores. Email. Ayuntamiento de Coslada. Plaza Mayor s/n 28821 Coslada (Madrid). Email: noepalomeque@ayto-coslada.es. Tlfo. 916278200. Ext. 3600. Página web: www.ayto-coslada.es.

Referencia normalizada: Palomeque, N. (2014). El enfoque de capacidades para el Trabajo Social. Trabajo Social Hoy, 73, 7-26. doi: 10.12960/TSH.2014.0013.

Nota: Las opiniones reflejadas en el artículo son de carácter personal y no se corresponden necesariamente con las del Ayuntamiento de Coslada ni con las de la Concejalía de Servicios Sociales y Mayores. 


\section{INTRODUCCIÓN}

Con este trabajo se pretende reflexionar sobre la intervención social que se realiza a diario como trabajador/a social, intentando incorporar en la misma el denominado enfoque de capacidades.

Los objetivos que se plantean con el mismo serían por un lado la reformulación del concepto de exclusión como privación de capacidades, entendiendo que no es un método efectivo para intervenir contra ella la mera provisión de recursos y servicios. Otro objetivo del artículo sería recalcar la importancia de dotar a las personas de libertad para decidir sobre el rumbo de su vida, siendo imprescindible para ello contar con las condiciones sociales necesarias que aseguren su dignidad. Siguiendo este argumento, otro propósito de esta reflexión es evaluar nuestra principal herramienta de lucha contra la exclusión como es la Renta Mínima de Inserción, analizando sus deficiencias y proponiendo como alternativa la introducción de la Renta Básica de Ciudadanía. Un último objetivo sería el de enfatizar unas pautas facilitadoras de la intervención desde los servicios sociales tendentes a lograr la participación del ciudadano, como forma de incrementar sus capacidades, es decir, de potenciar su agencia, entendiendo por la misma aquello que una persona es libre de hacer y alcanzar según las metas o los valores que esa persona considere importantes.

Se ha dividido el artículo en tres apartados principales. En primer lugar, se enuncia el concepto y las implicaciones del enfoque de capacidades, siempre en íntima relación con la intervención profesional. El análisis se centrará especialmente en las aportaciones realizadas por Martha Nussbaum. Posteriormente se reflexiona sobre la intervención partiendo de una teoría explicativa del contexto social. Se realiza desde una doble faceta: la exclusión provocada por nuestra sociedad y las herramientas profesionales, proveedoras de recursos y servicios con las que contamos para hacerle frente. Por último, se enuncian algunas formas facilitadoras de intervención, tomadas de la práctica diaria, que intentan compensar los déficits de capacidades en las personas. Con ellas se tiende a modificar las relaciones de poder y conseguir que la persona en situación de exclusión pase a ser participante y por tanto agente.

\section{EL ENFOQUE DE CAPACIDADES}

Esta teoría fue formulada en un primer momento por el economista y premio Nobel indio Amartya Kumar Sen. La finalidad que Sen (2011) persigue con su teoría es evaluar y valorar el bienestar, así como promover el desarrollo del individuo, de los grupos y de las comunidades en una determinada sociedad sin tener en cuenta indicadores exclusivamente económicos como el Producto Interior Bruto o los índices de crecimiento económico. Supone además un intento de superar las concepciones utilitaristas y de la teoría de los bienes primarios de John Rawls. 
Este enfoque pretende responder a la pregunta "¿Qué es capaz de hacer y ser cada persona...?" (Sen, 2011: 25). Por tanto, no se ocupa únicamente del bienestar total o medio del individuo, sino de las oportunidades disponibles para cada ser humano. Sostiene que todas las sociedades deben promover para sus ciudadanos un conjunto de oportunidades o libertades sustanciales, las llamadas capacidades, que las personas pueden elegir o no llevar a la práctica, los denominados funcionamientos. Veamos ambos conceptos con algo más de concreción:

- La capacidad de una persona se refiere a las diversas combinaciones de funcionamientos que puede conseguir, por lo tanto la capacidad es un tipo de libertad: la libertad fundamental para poder elegir entre distintas combinaciones de funcionamientos para llevar a cabo un modo o forma de vivir que es la más adecuada para cada persona. Serían sus oportunidades reales, las cosas que tiene libertad para ser o para hacer.

- Los funcionamientos serían las habilidades que tiene una persona para lograr ciertos resultados, acciones y formas de ser, siendo puestas en ejercicio. Serían las oportunidades efectivas o realizadas (Sen, 2011).

Es decir, desde esta perspectiva ya no se pregunta por la cantidad de recursos con que cuentan las personas para llevar un tipo de vida u otro, sino por lo que son capaces de hacer y ser realmente según lo que consideran valioso. La libertad como capacidad y la autodeterminación de la persona es central en este enfoque. Además, establece el concepto de agencia como superador al de la acción, ya que también incluye "la intención, el significado, la motivación y el propósito que los individuos imprimen a sus actividades" (Sen, 2000: 99), es decir el control y cierta predicción sobre aquello que hacen.

Por tanto, para este enfoque se podría definir la exclusión social como un proceso de carencia multidimensional de capacidades, ya sea de forma coyuntural o estructural, que impide a los individuos poder llevar a cabo los proyectos vitales que les resultarían valiosos. No considera los funcionamientos que realiza la persona como última medida de análisis. El interés está puesto en las libertades de las personas, es decir, en sus capacidades para poder elegir dichos funcionamientos. La exclusión no se define solo en términos de la privación de un determinado nivel de renta individual o familiar, considerándola como un medio que permitiría adquirir una determinada cantidad de bienes o acceder a ciertos servicios considerados como básicos; sino como aquella imposibilidad de alcanzar aquellos fines que a la persona le parecen más relevantes y útiles para sus vidas. Es decir, para Sen la exclusión no es tanto un problema de falta de medios materiales sino de déficits de libertades de las personas para llevar a cabo la vida que consideren oportuna. Para ello, Sen establece como centrales, parámetros como la calidad de la educación, el nivel de desarrollo intelectual de individuo, la capacidad crítica y reflexiva que le permita participar activamente en la vida diaria de su comunidad, lo que sin duda incrementará su nivel de productividad individual, y por tanto de la sociedad en su conjunto. 
A lo largo de la historia, los esfuerzos para luchar contra la exclusión social se han fundamentado en un modelo basado en los déficits o carencias de dicha población, definiendo a las personas, a los grupos y a las comunidades en términos negativos, sin tener en cuenta lo positivo y lo que funciona bien en el interior de los mismos. Este enfoque plantea que la lucha contra la exclusión debe traducirse en un proceso de expansión de las capacidades y libertades de las personas, para que estas sean las protagonistas de sus vidas. Por tanto se parte de la idea de que los sujetos son "agentes" y no "pacientes" de sus procesos de desarrollo. Es decir, el individuo no debe ser considerado como un ente pasivo que recibe ayuda, sino como su propio motor de generación y cambio de desarrollo y justicia social. Hay que huir de la idea de que el ciudadano en situación de exclusión es solo capaz de recibir, no vaya a producirse la paradoja que los instrumentos puestos en marcha puedan llegar a convertirse en elementos propiciadores de mayor exclusión social. La pasividad no construye ciudadanía.

Esta reflexión se centrará en las aportaciones realizadas por la filósofa norteamericana Martha C. Nussbaum, galardonada con el premio Príncipe de Asturias de Ciencias Sociales en el 2012, quien introduce en el enfoque el concepto de dignidad humana. Propugna como central en su teoría el concepto de dignidad humana, estableciendo como crucial una lista básica y concreta de capacidades centrales. Además, redefine el concepto de capacidades, entendiéndolas también como libertad, pero especificando dos tipos:

- Habilidades o facultades internas de la persona (capacidades intelectuales, emocionales, de salud, físicas, perceptivas...)

- Entorno o condiciones sociales, en cuanto al contexto social, político, económico...

Las primeras serían las capacidades internas. Las capacidades combinadas serían el fruto de la interacción entre las primeras y las segundas. Esta distinción entre las capacidades internas y las combinadas se corresponde con dos tareas diferentes que debe satisfacer toda sociedad digna, ya que se podrían producir las capacidades internas, pero cerrar por otros canales a sus ciudadanos las vías de acceso a la oportunidad de funcionar de acuerdo a esas capacidades. Por ello, el objetivo último del enfoque es que todos los ciudadanos de una sociedad deberían superar un cierto umbral de capacidad combinada, entendiéndolo no como un funcionamiento obligado y pautado, sino como una libertad sustancial para elegir y actuar (Nussbaum, 2012).

Además, hace una tercera diferenciación, llamando "capacidades básicas a aquellas que son innatas en cada ser humano y que hacen posible su posterior desarrollo y formación" (Nussbaum, 2012: 43): 
"La noción de dignidad está estrechamente relacionada [...] con la idea de capacidad básica como aquella referida a lo más interno como los anhelos, esfuerzos, motivaciones, deseos y que exige ser desarrollado (la denominada conación)" (Nussbaum, 2012: 51).

El concepto de dignidad también nos lleva a la idea de que la elección de las políticas públicas deben ser aquellas que protejan y apoyen la agencia o la capacidad de acción del individuo, en lugar de otras que infantilicen a las personas o las traten como receptoras pasivas de prestaciones, que para poder seguir percibiéndolas son "obligadas" a realizar funcionamientos que, o no tienen la capacidad suficiente para realizar, o que simplemente no entran dentro de sus planes de vida. Una vida con dignidad se constituye en la medida en que las personas cuentan con un conjunto de capacidades para funcionar, que les permiten alcanzar aquellos aspectos que consideran valiosos para sus vidas. Así, las condiciones sociales, políticas, culturales, económicas y familiares pueden impedir que las personas opten por funcionar conforme a una capacidad interna ya desarrollada, o incluso peor, afectando estas condiciones negativas a lo más íntimo de las personas, atrofiando sus capacidades internas. Por este motivo, en aras a analizar las capacidades combinadas, en este trabajo se atenderá al fomento de la agencia individual enmarcándolo en la sociedad excluyente donde nos ha tocado vivir (Nussbaum, 2007).

Asimismo, Jonathan Wolff y Avner De Shalit, en su libro Disadvantage (aún no traducido al español) introducen varios conceptos que pueden ser realmente útiles para el trabajador social que intervenga sobre la agencia de los ciudadanos. El primero de ellos es el de seguridad en las capacidades, refiriéndose a que las políticas públicas deben garantizar las capacidades de los ciudadanos de forma que puedan contar con ellas en el futuro, es decir, poniéndolas a salvo de los vaivenes de las decisiones políticas. Además, también introducen los conceptos de capacidad fértil y desventaja corrosiva. Por capacidad fértil entienden aquella que, al cultivarla, favorece también la aparición de otras capacidades relacionadas. Las desventajas corrosivas constituyen déficits que tienen influencia en varios o muchos aspectos vitales de la persona (Wolf y De Shalit, 2007).

Nussbaum se pregunta sobre lo que es una vida realmente humana, y las respuestas que parece dar tienen que ver con su afirmación intuitiva de que hay determinadas funciones centrales que, si estuvieran ausentes, revelarían su ausencia. Se trataría de establecer un mínimo bajo el cual no se pueda hablar de una vida verdaderamente humana, y para poder establecer ese nivel mínimo, Nussbaum ofrece una lista de diez capacidades que actuarían como requisitos básicos para una existencia digna. Esta lista que describe la autora es la siguiente:

1. Vida. Poder vivir hasta el término de una vida humana de duración normal; no morir de forma prematura o antes de que la propia vida se vea tan reducida que no merezca la pena vivirla. 
2. Salud física. Poder mantener una buena salud, incluida la salud reproductiva; recibir una alimentación adecuada; disponer de un lugar apropiado para vivir.

3. Integridad física. Poder desplazarse libremente de un lugar a otro; estar protegidos de los ataques violentos, incluidas las agresiones sexuales y la violencia doméstica; disponer de oportunidades para la satisfacción sexual y para la elección en cuestiones reproductivas.

4. Sentidos, imaginación y pensamiento. Poder utilizar los sentidos, la imaginación, el pensamiento y el razonamiento, y hacerlo de un modo "verdaderamente humano", un modo formado y cultivado por una formación adecuada que incluya (pero no esté limitada a) la alfabetización y la formación matemática y científica básica. Poder usar la imaginación y el pensamiento para la experimentación y la producción de obras y actos religiosos, literarios, musicales o de índole parecida, según la propia elección. Poder usar la propia mente en condiciones protegidas por las garantías de la libertad de expresión política y artística, y por la libertad de práctica religiosa. Poder disfrutar de experiencias placenteras y evitar el dolor no beneficioso.

5. Emociones. Poder sentir apego hacia cosas y personas externas a nosotros mismos; poder amar a los que nos aman y se preocupan por nosotros, y sentir duelo por su ausencia; en general, poder amar, apenarse, sentir añoranza, gratitud e indignación justificada. Que no se malogre nuestro desarrollo emocional por culpa del miedo y la ansiedad. (Defender esto supone promover formas de asociación humana que pueden ser demostrablemente esenciales para su desarrollo).

6. Razón práctica. Poder formarse una concepción del bien y reflexionar críticamente acerca de la planificación de la propia vida. Esto supone la protección de la libertad de conciencia y de observancia religiosa.

7. Afiliación. A) Poder vivir con y para los demás, reconocer y mostrar interés por otros seres humanos, participar en formas diversas de interacción social; ser capaces de imaginar la situación de otro u otra. Esto implica proteger instituciones que constituyen y alimentan tales formas de afiliación, así como la libertad de reunión y de expresión política. B) Disponer de las bases sociales necesarias para que no sintamos humillación y sí respeto por nosotros mismos; que se nos trate como seres humanos de igual valía que los demás. Esto supone introducir disposiciones que combatan la discriminación por razón de raza, sexo, orientación sexual, etnia, casta, religión u origen nacional.

8. Otras especies. Poder vivir una relación próxima y respetuosa con los animales, las plantas y el mundo natural.

9. Juego. Poder reír, jugar y disfrutar de actividades recreativas.

10. Control sobre el propio entorno. A) Político. Poder participar de forma efectiva en las decisiones políticas que gobiernan nuestras vidas; tener derecho a la participación política y a la protección de la libertad de expresión y de asociación. B) Material. Poder poseer propiedades (tanto muebles como inmuebles) y ostentar derechos de propiedad en igualdad de condiciones con las demás 
personas; tener derecho a buscar trabajo en un plano de igualdad con los demás; estar protegidos legalmente frente a registros y detenciones que no cuenten con la debida autorización judicial. En el entorno laboral, ser capaces de trabajar como seres humanos, ejerciendo la razón práctica y manteniendo relaciones valiosas y positivas de reconocimiento mutuo con otros trabajadores y trabajadoras (Nussbaum, 2012: 53-55).

Por tanto, se observa que el principio básico por el que responde este enfoque es que la persona es un fin en sí misma. Este énfasis en el individuo es muy importante ya que con demasiada frecuencia, los sistemas de prestaciones que desean reequilibrar los déficits de las personas toman su nivel de análisis en la unidad familiar, como sucede por ejemplo con nuestra principal herramienta de lucha contra la exclusión: la Renta Mínima de Inserción. En el siguiente apartado, seguiremos reflexionando sobre este aspecto.

\section{LA EXCLUSIÓN SOCIAL COMO FACTOR ESTRUCTURAL}

Podríamos resumir todo lo afirmado hasta aquí en la idea de que las condiciones de vulnerabilidad y exclusión social no pueden ser erradicadas a través de la lógica de la distribución de bienes y recursos económicos, sino que están vinculadas a causas estructurales, culturales y valorativas. Analizando cada una de las capacidades centrales propuestas por Nussbaum, se observa con bastante desasosiego que nuestra sociedad ni siquiera procura un umbral mínimo digno en muchas de ellas.

A estos procesos de exclusión tan acentuados a los que nos enfrentamos a diario, que no son fenómenos naturales ni propios de la naturaleza humana, sino que están motivados en gran parte por la estructura social que nos rodea y que pasaremos a analizar, se añade la ineficacia de los sistemas de protección social con los que se cuenta para compensar la precariedad de capacidades combinadas de los ciudadanos.

\subsection{LAS CINCO CARAS DE LA OPRESIÓN}

Según la filósofa y politóloga estadounidense Iris Marion Young, la exclusión de la sociedad es una forma de opresión que hunde sus raíces en prácticas legales y procesos sociales que sistemáticamente sitúan en desventaja a ciertas personas frente a otras. Así, para ella, la exclusión sería aquella forma de opresión como fenómeno estructural que impide a ciertos grupos sociales desarrollarse y participar en la vida comunitaria (Young, 2000). Es decir, las personas se encuentran oprimidas cuando, derivadas de ciertas actuaciones institucionales y sociales, ven mermadas sus capacidades y habilidades para organizarse y comunicar a los demás sus inquietudes. Partiendo de dicha concepción, distingue cinco caras de la opresión: explotación, marginación, carencia de poder, imperialismo cultural y violencia. 
La explotación se produce por la desigualdad extrema del proceso de transferencia de los resultados o productos del trabajo debido a la lógica de distribución de recursos imperante en la sociedad.

Una segunda cara de la opresión es la marginación. Por marginación entiende aquellas situaciones en que el sistema no quiere o no puede usar a ciertos individuos que quedarían excluidos de la participación útil en la sociedad y que, al estar estrechamente relacionadas las nociones de independencia y autonomía con la noción de ciudadanía, quedarían sujetos a un tratamiento paternalista y degradante ante las administraciones públicas o entidades privadas. Un ejemplo serían aquellas personas que están excluidas de participar en las actividades que socialmente se asocian a un empleo formal y remunerado.

Una tercera expresión de la opresión es la carencia de poder. La carencia de poder, al estar íntimamente relacionada con la respetabilidad profesional y laboral, se manifiesta en numerosas prácticas cotidianas a través de conductas racistas y sexistas. Young destaca la división social del trabajo entre trabajadores especializados (profesionales) y los no especializados, en donde los primeros gozan de un status que les confiere autoridad y poder en la sociedad, mientras que los segundos usualmente se dedican a empleos con poca o casi nula autonomía, en donde ejercen poca creatividad y análisis, y en los que no desarrollan habilidades técnicas relevantes. $Y$ esto es algo que generalmente no se limita a lo laboral, sino que los profesionales gozan de una respetabilidad de la que en pocas ocasiones pueden disfrutar quienes ocupan los cargos menos valorados, ya se trate de miembros de minorías raciales, sexuales, etc. Esta circunstancia genera una carencia de poder y una merma de respeto e influencia en la vida social del colectivo menos especializado, normalmente las personas que acuden a los servicios de protección, siendo esta brecha cada vez más acentuada.

Una cuarta faceta de la opresión es el imperialismo cultural. Esta faceta conlleva la universalización de la experiencia y los valores del grupo dominante socialmente, quien proyecta sus propias experiencias como representativas y homogeneizadoras de la sociedad en su conjunto, entendiendo tal categorización como neutral. Las perspectivas de los grupos minoritarios, en cambio, se volverían invisibles e irían adquiriendo gradualmente connotaciones negativas, al ser los miembros del grupo definidos con caracteres estereotipados y catalogados no ya como distintos, sino como insignificantes, indeseables y en algunos casos incluso a erradicar.

Finalmente, la quinta cara de la opresión es la violencia estructural. Es verdad que los incidentes violentos hacia ciertas personas por el hecho de su pertenencia a grupos o minorías sociales, constituyen hechos aislados. Aunque no hay que despreciar que cada vez se están haciendo más presentes. No olvidemos en España los trágicos sucesos de El Ejido y las agresiones a minorías africanas en Salt. Además, no solo se 
refiere a los ataques físicos a los miembros de los grupos marcados socialmente, sino también todas aquellas formas de acoso o intimidación provocados con la intención de ridiculizar o humillar a dichas personas. Se contemplan todas estas conductas no ya como el acto particular de un individuo concreto, sino atendiendo al contexto social que lo rodea y que hace de estos actos hechos posibles e incluso, en los casos más extremos, aceptables (Young, 2000).

Con esta aportación se evidencia que la exclusión la provocan elementos estructurales, que afectan de modo diverso a cada individuo, y también que esos elementos estructurales son propios de una sociedad que en sí contiene el germen de la exclusión, entendida como una negación de la ciudadanía al impedir a las personas el acceso al ejercicio de los derechos civiles, políticos y socioeconómicos.

Partiendo de todo lo expuesto, el derecho no puede hacer caso omiso de estos desbarajustes escandalosos que han sido históricamente institucionalizados, pues se constituiría en un elemento más de su perpetuación. Por este motivo, el enfoque de las capacidades propuesto por Nussbaum es presentado, además de como una base filosófica de los derechos básicos y de la dignidad de los seres humanos, como una verdadera teoría positiva, es decir enmarcada en el sistema normativo legal de los Estados, en la que se describa el umbral mínimo de cada una de las capacidades centrales descritas, y que además no tenga un mero carácter programático sino que sea vinculante para los poderes públicos.

\subsection{RENTA MÍNIMA DE INSERCIÓN VERSUS RENTA BÁSICA DE CIUDADANÍA}

En este momento, la exposición se va a centrar en la principal herramienta legal con la que cuentan los/as trabajadores/as sociales para llevar a cabo las intervenciones sociales de lucha contra la exclusión, la llamada en la Comunidad de Madrid, Renta Mínima de Inserción. Este programa consiste en, mediante un estudio previo de las condiciones económicas en las que se encuentra cada familia a través de un baremo económico establecido, facilitar una cantidad económica de ámbito familiar a cambio de que los distintos miembros de la unidad familiar se comprometan a unos objetivos establecidos, normalmente búsqueda de empleo. La renta estará vigente mientras no cambien las circunstancias económicas o de residencia de todos los miembros de la unidad familiar y sigan cumpliendo el plan de actuación contenido en un contrato de inserción. Es decir, nos encontramos ante una prestación condicionada: para poder ser otorgadas, necesitan pasar por una comprobación previa de recursos además de cumplir con otras condiciones y requisitos. Este tipo de ayudas son propias de nuestro sistema legal de protección y son normalmente gestionadas desde los servicios sociales. Y desde aquí, me pregunto ¿por qué utilizamos una prestación condicionada y no introducimos en nuestro ordenamiento jurídico una prestación universal como la denominada Renta Básica de Ciudadanía? Porque se comprobará que más que potenciar 
las capacidades de los beneficiarios, lo que hacemos es reproducir los esquemas opresivos de los que hablaba Young y a los que ya hemos hecho referencia.

Cuando una persona acude a los despachos de los/as trabajadores/as sociales demandando una ayuda económica, lo primero que hace el profesional es evaluar si cumple los requisitos para poder optar a la misma, enfocando su atención además de en las ayudas municipales disponibles en el municipio para el que trabaje, en la Renta Mínima de Inserción (en adelante RMI). Ello es debido a su naturaleza periódica e indefinida, siempre que no cambien las condiciones económicas o sociales de su entorno familiar.

El primer requisito que se examina es el de carencia de rentas. Esta comprobación es claramente humillante. La legislación de la Comunidad de Madrid establece una serie de recursos económicos computables que pasan desde declaraciones juradas de ingresos, a solicitar judicialmente una pensión de alimentos o una sentencia de divorcio, a presentar el recibo del alquiler de una habitación (y que el contrato de arrendamiento de toda la vivienda no esté a su nombre, porque le van a imputar como propias las rentas que los demás inquilinos aportan por el pago de sus respectivas habitaciones), hasta acreditar que no tiene derecho a ninguna prestación de todos los organismos posibles (Ley de Dependencia, prestaciones del Servicio Público de Empleo, de la Seguridad Social, etc...) e incluso a obligar a los parientes con los que ya no convive a que le presten la asistencia necesaria establecida en el artículo 142 y siguientes del Código Civil.

Una vez hecho esto, analizamos el resto de los requisitos que suelen ser residencia continuada y efectiva durante al menos un año demostrada por certificado de empadronamiento; formar parte de una unidad familiar independiente; suscribir un compromiso de participar en un programa de inserción individual tendente normalmente al empleo; escolarización de los hijos; por supuesto no haber causado baja voluntaria en el trabajo en los últimos seis meses, etc...

Es decir, se establecen funcionamientos como objetivos sin tener en cuenta las propias capacidades de la persona..., que además perpetúan la opresión de la sociedad, siendo propiciadoras de marginación y de imperialismo cultural (Young, 2000).

El subsidio condicionado siempre se percibe posteriormente a la comprobación de la no superación de una cantidad de recursos determinada. Una vez llegados a cierta cantidad, los ingresos condicionados tocan techo, es decir no se puede percibir más, independientemente del número de personas que compongan la unidad familiar. (Por ejemplo, en la Comunidad de Madrid el techo es de 532,51 Euros. Este techo corresponde a 3 miembros y cobrarían lo mismo si fueran 5, 6 o más miembros). Si se percibe alguna renta adicional se pierde todo o parte del subsidio. Además, debido a los umbrales de renta tan exiguos permitidos, gran parte de la población que puede estar en situación de 
exclusión o de vulnerabilidad y que podrían beneficiarse de estos programas, no pueden entrar dentro del sistema. Con la entrada en vigor del nuevo reglamento aprobado por el Decreto 126/2014, de 20 de noviembre, se legitima un nuevo escándalo en cuanto a la determinación de la cuantía de la Renta Mínima de Inserción, castigando a aquellas unidades familiares que compartan un mismo marco físico de alojamiento, aunque no tengan ningún tipo de vínculo o parentesco, a una reducción de un 20\% o de un $30 \%$ según si son dos o más unidades familiares las que comparten la misma vivienda. El legislador hipócritamente debe imaginarse que con 375 euros se garantizan las necesidades de alojamiento y manutención de una persona y que hay que reducir el importe de la prestación a aquellas personas que pretenden "ahorrar", compartiendo una misma vivienda como si a la gente le gustara vivir compartiendo habitaciones. Este recorte es una medida indigna y vergonzosa y deberá tener pronta respuesta judicial para intentar recomponer la dignidad de las personas que perciben esta prestación.

En cambio, la Renta Básica no requiere ningún tipo de comprobación ya que su asignación es universal, se percibe antes de que se llegue al nivel de exclusión y su cuantía se puede acumular a cualquier otro ingreso, que posteriormente pasará por la criba fiscal.

Pero, ¿a qué me refiero cuando hablo de la Renta Básica, también llamada por algunos autores Salario Ciudadano? La formulación actual de la Renta Básica se debe a Philippe Van Parijs, catedrático de Ética y Economía de la Universidad Católica de Lovaina. La Renta Básica (RB en lo sucesivo) es un pago que el Estado realizaría periódicamente a cada ciudadano o residente en su territorio, de forma individual e incondicional, independientemente de cualquier otro ingreso que pueda tener, así como de su situación familiar o laboral. Es decir, una renta por el mero hecho de ser ciudadano. Así entre sus principales características, como las describen los profesores Van Parijs y Vanderborght, podríamos señalar las siguientes:

- La universalidad

La RB es un derecho universal, es decir, la percibirían todos los miembros de una comunidad política independientemente de factores como la actividad económica, el género o la edad, e incluso llevado a su extremo, de su situación legal.

- La incondicionalidad

El acceso a la RB no está sujeto a ningún tipo de comprobación de recursos, ni a la inexistencia de un mínimo nivel patrimonial o a la imposibilidad de recurrir a cualquier tipo de derecho de alimentos por parte de familiares. Tampoco se exigen contraprestaciones laborales, ni la disponibilidad a aceptar cualquier empleo, ni el compromiso de realizar acciones de formación profesional. Se otorga al individuo en base a su dignidad como persona humana y no en cuanto a trabajador, real o potencial. Asimismo tampoco se valora la composición o la situación familiar. 


\section{- La individualidad}

La RB tiene como beneficiario al ciudadano individualmente, no es una prestación exclusivamente familiar. Otra cuestión distinta es, como indican algunos autores, el establecimiento de diferentes cuantías en virtud de las diferentes edades de los ciudadanos (Van Parjis y Vanderborght, 2006).

La RB por sí misma no garantizaría un aumento cualitativo de las capacidades de los ciudadanos para que estos pudieran revertir en funcionamientos valiosos para ellos, ya que, según Sen, habría que tomar en consideración "las heterogeneidades personales, las diversidades en el ambiente físico, las variaciones en el clima social y las diferencias en perspectivas relacionales" (Sen, 2010: 285), pero sin duda sí que permitiría la satisfacción de las necesidades vitales o biológicas de los mismos en un umbral determinado, y permitiría a los profesionales de la intervención social llevar a cabo tareas de empoderamiento y de fortalecimiento del capital social que ampliara la esfera de libertad de las personas, facilitando que lograran acceder a metas o proyectos que consideraran importantes.

Todos estos requisitos de comprobación para obtener la RMI, unido al gran aumento de sus solicitantes y al recorte de los tramitadores, conlleva que la Administración tarde en resolver estos expedientes, según mi propia experiencia profesional, alrededor de un año. Ello obliga a intervenciones meramente paliativas y reproductoras a medio plazo de la exclusión y a la sensación de que las personas que acceden, después de tanto tiempo, ocupan algún lugar en el mercado sumergido.

Además, los trabajadores sociales deben afrontar la llamada trampa de la pobreza que los ciudadanos con mayor o menor éxito intentan cada día. Esta trampa consiste en grandes líneas en que, al tener los subsidios condicionados carácter subsidiario de otra fuente de ingresos, cuando a los ciudadanos les ofrecen un empleo, que normalmente va a tener unas condiciones muy precarias (en cuanto a ingresos y duración del contrato), estos se ven obligados a analizar si es conveniente o no su aceptación, ya que si acepta se le retirará la prestación o se verá sustancialmente reducida. Además, debe valorar el cambio en la regularidad de los pagos que supone la RMI por la incertidumbre de los pagos del nuevo trabajo.

También cabe incluir en esta dimensión el miedo ante la inseguridad de no poder satisfacer las expectativas del empleo. Efectivamente, si se pierde el trabajo, existe la posibilidad de volver a pedir la reincorporación al programa, pero los retrasos administrativos ya mencionados son bastante disuasorios. Por tanto, analizará si le compensa o no. Y normalmente el trabajo que le compensa es aquel que no le ofrece ningún tipo de contrato ni cobertura social, y en el que el salario es en negro. Esta idea de la seguridad en las capacidades, en este caso la de la satisfacción económica básica, ya se esgrimió al mencionar las aportaciones de Wolff y De Shalit. Un caso muy parecido sucede con las personas que reciben prestaciones o subsidios de desempleo. 
Este tipo de situaciones complica aún más la gran vulnerabilidad de estas personas, que se ven abocadas a sobrevivir en el mercado informal, normalmente en el servicio doméstico o la construcción, sin que las administraciones hagan algo por evitarlo, y al menos en el mejor de los casos, se provoca en los beneficiarios de estos subsidios la sensación de fracaso vital, siendo muy difícil contrarrestar este vacío con las intervenciones profesionales.

La RB sería por tanto una propuesta de ingreso mínimo pagado por el Estado a cada persona para facilitar la cobertura de un umbral mínimo de capacidades y, sobre todo, para garantizar el derecho a la existencia y a la dignidad humana.

Nuestro modelo de sociedad tiene como eje principal el empleo. De hecho, a pesar de las situaciones tan dramáticas de desempleo y que ya es considerado oficialmente como un problema estructural, situándose según las tasas oficiales por encima del 24\% de la población activa, todavía hay un mito que relaciona la autorrealización personal con el trabajo. Esta situación está provocando un malestar psicosocial, sobre todo cuando uno no considera que su trabajo está fomentando todas sus capacidades ya sea porque le infravaloran o le sobrevaloran con la presión que ello lleva aparejado. Esta sensación se incrementa en los casos de las personas en búsqueda activa, y yo diría desesperada, de empleo sin alcanzar el éxito.

Y no es aceptable que en aras de una flexibilidad y de una exigencia de adaptación a los cambios, se obligue a los ciudadanos a aceptar auténticos trabajos basura en unas condiciones inaceptables para la dignidad humana. La introducción de esta renta fomentará el aumento de la calidad del empleo en cuanto a condiciones y a retribuciones, y permitirá al ser humano poder optar por otras actividades o funcionamientos que también generan riqueza nacional, como cuidar convenientemente a los hijos y no someterlos a intensas jornadas de escuela infantil o colegios, realizar actividades tecno científicas o cibernéticas sin tener que marcharse al extranjero para poder subsistir por ellas, e incluso realizar actividades artísticas para el goce y disfrute del resto de la sociedad.

Pero ese sistema no solo sería el comienzo de la libertad de contratación entre empleados y empresarios, sino que reforzaría también enormemente la esfera de la libertad en las relaciones interpersonales. Veamos algunos ejemplos. Actualmente, una persona empleada, aunque le desagrade profundamente su trabajo, con frecuencia se ve obligada a seguir en él no solo porque no dispone de medios para arriesgarse al desempleo y, naturalmente, si abandona el trabajo, no tiene derecho a los beneficios de la prestación, sino que se ve auténticamente influido por la situación de desempleo generalizado en el que nos movemos que le hacen justificar el mismo con términos como "al menos tengo un trabajo". Pero, en realidad, las consecuencias psicológicas de esa situación son devastadoras: el hecho mismo de que no puede arriesgarse a ser despedido tiende a hacerle sumiso respecto de su jefe. Aceptará por tanto cualquier acoso o atentado contra su dignidad, renunciando 
incluso a elementos primarios de su persona. O pensemos en la mujer que está sufriendo un auténtico calvario y cuya única razón para no separarse de su marido es por los déficits económicos que ello le produciría hasta que pudiera encontrar algún trabajo, y eso si no tiene que hacerse cargo de unos hijos. O de aquella persona de mediana edad que, tras perder su empleo, debe recomponer su proyecto vital asumiendo incluso la vuelta a su entorno familiar de partida, que además del sentimiento de fracaso y de ser una carga, puede llevar aparejado el aumento de la precariedad sobre todo si solo hay una pensión y es de baja cuantía. El campo de la libertad personal se ampliaría enormemente con una garantía social que acabara con la dependencia económica de las personas a todos los niveles (de su cónyuge, de sus padres, de su jefe) que ya no se verían sometidos a la presión de caer irremediablemente en la exclusión social. En estos tiempos de inestabilidad laboral, donde las recientes reformas normativas han avivado el riesgo al desempleo y por tanto a la cobertura de ingresos, esta renta permitiría el mantenimiento de unos mínimos vitales para el conjunto de la población, no ya porque hagan algo, sino por el hecho de existir.

Evidentemente, como hemos analizado con las aportaciones de Young, las fuerzas (medios de producción y fuerza de trabajo) son completamente desiguales y las reformas del mercado laboral las están acentuando más con medidas como la desaparición de los convenios colectivos, el abaratamiento de costes de despido y la legalidad de la modificación unilateral por parte de las empresas de las condiciones en cuanto a horarios, actividades y salarios, etc. Ahora mismo muchas personas se enfrentan al dilema de aceptar un empleo basura o de continuar en el paro.

Con todo ello, tampoco se quiere desvirtuar el papel del trabajo en la sociedad como elemento clave y básico de generación de riqueza, y más teniendo en cuenta que las rentas de trabajo son un elemento sustentador muy importante de cualquier política fiscal. Lo que se pretende con esta propuesta es que el establecimiento de una RB sería un elemento consustancial de equidad en nuestro sistema económico. Se necesitan buscar otros factores, además de los tradicionales, de relación entre los medios de producción y fuerza de trabajo, que determinen la capacidad de los miembros individuales de la comunidad para subsistir y prosperar.

Además, parte del esfuerzo económico para su implantación quedaría cubierto con los impuestos que gravan el consumo, ya que evidentemente este aumentaría al tener las familias más ingresos disponibles, con lo que se produciría una relación directa en la oferta de empleo.

Y si ahora se facilitara su implantación ¿qué hacemos con toda nuestro sistema social actual, bastante disperso por cierto, que compone principalmente nuestro cuarto pilar del Estado de Bienestar? En concreto, me refiero al sistema de servicios sociales y a las pensiones no contributivas. Y la respuesta es muy sencilla: eliminamos de raíz todo subsidio, ayuda o prestación condicionada. 
Algunas opiniones contrarias afirman que la RB fomentaría la pereza y el parasitismo. Es necesario producir y para ello es necesario trabajar. Ya he comentado algo de esto anteriormente, pero sintetizo indicando que hay que clarificar qué se entiende por trabajo y qué se entiende por actividad productiva, ya que no produce únicamente riqueza la actividad retribuida. Además, nadie discute esta misma idea de la reciprocidad retributiva en otros pilares básicos como la sanidad y la educación. Por ejemplo, nadie entendería que a un ciudadano completamente cuerdo y consciente que no hace más que fumar después de haber sido advertido por el personal sanitario del grave perjuicio que causa él mismo a su salud y al resto de la sociedad por el coste tan elevado de su tratamiento, cuando llegara al hospital con un cáncer de pulmón, no le dejaran acceder al mismo porque no ha contribuido al sostenimiento de su salud, sino todo lo contrario. Igual sucedería con un estudiante que no aprueba las asignaturas. ¿Se le debería excluir por ello del sistema educativo que tanto nos cuesta a todos...?

Y ahora en este punto, entramos en la tarea de la financiación. ¿Es viable económicamente la RB?

La respuesta inmediata sería que habría que financiarlo con un sistema impositivo distinto al que tenemos. Varios economistas han presentado algunas alternativas al respecto. La principal de ellas es el llamado Impuesto Negativo sobre las Rentas (INR), que sería un crédito reembolsable por el Estado si, tras la declaración de ingresos, no se supera un nivel mínimo. Esta medida, que no sería una RB en sentido estricto, ha sido planteada, entre otros, por economistas prestigiosos como James Tobin. Existen también algunos estudios en nuestro entorno, como el de los profesores Arcarons, Raventós y Torrens del año 2013, en el que hacen una simulación de implantación de la Renta Básica en el ámbito de Cataluña, en el que a rasgos generales se establecería un único tipo impositivo (49,58 \%), se eliminarían todas las deducciones, desgravaciones o exenciones fiscales y se suspenderían todas las prestaciones sociales condicionadas. Además, iría acompañado de más cambios legislativos tributarios, como un nuevo tipo en el impuesto sobre sociedades, un nuevo impuesto de transacciones financieras y otro sobre la riqueza, restricciones al sistema de módulos y a las Sicav (Arcarons et al., 2013). Desgraciadamente, en este artículo no podemos detenernos más en esta cuestión.

\section{INTERVENCIÓN DE LOS SERVICIOS SOCIALES DESDE EL ENFOQUE DE CAPACIDADES}

Los servicios sociales municipales de atención primaria se configuran como el último sistema de cobertura de las necesidades sociales, poniendo a disposición de los ciudadanos un conjunto de prestaciones básicas, tanto técnicas o de servicios como 
económicas. Además, por mandato legal, tiene encomendadas ciertas funciones de protección, específicamente hacia los menores, pero también hacia otros colectivos por su situación de incapacidad para poder elegir el sentido que toma su vida. Este trabajo no se refiere a esta última función.

Estas prestaciones se configuran de forma claramente dispersa y en colisión con otros organismos públicos: como el SEPE, la Seguridad Social, etc., y con gran influencia de los mismos. Además, su concesión tiene bastante carácter discrecional y desigual al no estar regulados legalmente de manera uniforme. A este hecho se le une la opacidad y el desconocimiento de la ciudadanía sobre los servicios de protección social que ofrece cada entidad local.

Debido a esta influencia de los otros sistemas protectores, de carácter predominantemente económico, se corre el riesgo desde los servicios sociales de confundir el objeto con los recursos materiales de los que disponemos, sustituyendo nuestra faceta de acompañamiento social por la de la mera gestión de prestaciones económicas. Ambas son importantes, eso sí, reducir la intervención social a la gestión administrativa de prestaciones y ayudas, la diluye e incapacita para sus fines.

Para el enfoque de capacidades, "la exclusión es un concepto multidimensional que hace referencia a un proceso de pérdida de integración o participación del individuo en la sociedad, en uno o varios de estos ámbitos: económico (en la producción o el consumo), político-legal (participación política, sistema administrativo, protección social...) y social-relacional (ausencia de redes o problemática dentro de las redes sociales o familiares)" (EAPN, 2012: 14).

La idea efectiva de la participación de la persona en la intervención profesional es crucial. Participar supone, por un lado, la intervención activa de las personas, la agencia, en la construcción de su propia realidad y por otro, una dinámica de intercambio mutuo y sentido crítico que produce una transformación del entorno en el cual participa.

Por tanto, la idea de participación activa de las personas en situación de exclusión social en sus procesos vitales comprende el desarrollo personal y la reordenación de su proyecto vital, así como su reconocimiento como sujetos con dignidad y en los que hay que promover la libertad de elección, fortaleciendo sus capacidades y posibilitando su acceso a espacios sociales de los cuales está total o parcialmente excluido. Es decir, toda intervención social debe partir de una primera fase de sensibilización tendente a la concienciación de la persona de su propia situación y de los derechos y deberes que le asisten como ciudadano para que, desde aquí, se pueda emprender un proceso de desarrollo de sus propias habilidades, actitudes y capacidades que le conduzcan a tomar sus propias decisiones. Por tanto, es una tarea que solo puede ser empren- 
dida por la propia persona, asumiendo el profesional un rol facilitador de búsqueda, reconstrucción, activación o devolución de las capacidades perdidas, destruidas, desactivadas o sustraídas.

Por ello no se puede hablar de participación. No podremos nunca considerar a la persona en situación de exclusión como alguien agente y responsable de su vida, como un ciudadano de pleno derecho, si los poderes públicos no garantizan con carácter previo el establecimiento de un umbral mínimo de las diez capacidades de Nussbaum anteriormente explicitadas. No se puede participar si ese día no se ha comido..., por lo que no se puede acabar con las intervenciones paliativas o reproductivas.

Además, al profesional se le debe exigir una reflexión previa y personal que le haga consciente de su modo de interpretar la realidad, sus estereotipos y prejuicios, sus preferencias ideológicas, políticas o religiosas, construir y examinar su propio sistema de valores y un esfuerzo para comprender y, más importante, aceptar (que no justificar) el propio funcionamiento de la persona, que a veces se sitúa en parámetros muy diferentes a los suyos. Además, es imprescindible un compromiso personal y una militancia activa en defensa de los derechos sociales de las personas con las que trabaja.

Asimismo, la participación no puede ser entendida como un hecho aislado o como un resultado puntual. La participación en esencia contiene la idea de proceso, es decir, nos conduce a la propia historia, a la propia dinámica vital de cada persona, por lo que no hay metas ni objetivos predefinidos, sino que estos serán los que el propio ciudadano vaya construyendo y retroalimentando. Idea de proceso como transformación para adaptarse a los cambios, a los retrocesos y a las mejoras. No se trata de que, como Sísifo, nos dejemos todo el esfuerzo en llevar nuestra gran roca ladera arriba para que una vez en lo alto, esta caiga una y otra vez...

Este enfoque, como ya hemos mencionado, no se basa en las carencias a cubrir sino en las potencialidades a descubrir. Esto no quiere decir que haya que obviar las dificultades y las carencias de todo tipo, pero el esfuerzo debe comenzar por utilizar las capacidades presentes. Es más fácil empezar por lo que ya existe que por lo que falta. En este sentido, la labor del profesional consistiría en ayudar a colocar las piezas que trae la persona para recomponer un puzzle, manteniendo en todo momento una conducta de pleno respeto a las decisiones tomadas por el ciudadano, aunque no le parezcan las más acertadas.

Además, un proceso de desarrollo de las capacidades, y por tanto de las libertades de los individuos agentes, requiere indudablemente de un protagonismo importante de las propias personas a la hora de definir el punto de partida del proceso, sus contenidos y los pasos a dar, facilitando que se pueda abordar lo que más le preocupa o interesa en un momento dado. La persona debe reconocerse como agente de su propio proceso, 
asumiendo su responsabilidad y redescubriendo sus propias capacidades que dan como resultado los funcionamientos realizados, siendo conscientes de que nadie tiene un control absoluto sobre su propio proceso personal, y menos quienes se encuentran en proceso de exclusión. Pero recuperar parcialmente el control de la propia vida no puede hacerse sin dar a los sujetos un espacio amplio de libertad que permita articular las capacidades y las dificultades, los apoyos necesarios y la propia responsabilidad en sus funcionamientos.

La participación debe realizarse en un marco democrático y tendente a que las personas excluidas influyan en la toma de decisiones, muchas de ellas de índole política, que están afectando seriamente a sus condiciones de vida. Debe facilitar el acceso al poder a aquellos colectivos que tradicionalmente han sido ignorados por aquellos que toman las decisiones en cuanto a las prioridades sociales y, por supuesto, en la asignación de los recursos y en los proyectos a los que van destinados. Hemos reducido la democracia al derecho de sufragio, aunque no cabe duda de que para generar participación debemos comenzar por insistir en la ciudadanía en el pleno ejercicio de este, algo que parece que se obvia o se reduce a una mera elección personal en nuestros procesos de intervención social.

Por este motivo, la idea de participación supone aceptar el concepto de diagnóstico compartido, es decir, renunciar al desequilibrio profesional que considera al técnico como el único capacitado para establecer un diagnóstico y apostar por la identificación de la situación de común acuerdo entre los profesionales y las personas. Hay que huir del miedo a la pérdida de poder y control tecnocrático, porque la intervención social se basa precisamente en aumentar el poder y la influencia de las personas para las que trabajamos, evitando dependencias y cronicidades. Para ello, los profesionales utilizamos el concepto de la generación de vínculo, como aquella aptitud que nos permite acercarnos a la persona con el objeto de facilitarle elementos de superación, afirmación y resolución para afianzar sus capacidades y transformarle en un actor social. Pero la generación de esta aptitud relacional tiene sus límites; esta debe ser significativa pero no intensa, evitando una identificación excesiva que más parecería encubrir ciertas carencias del profesional y que favorece todo lo contrario a lo pretendido con la intervención: la sustitución de la persona por el profesional, la excesiva afectación empática que paraliza la intervención o la confusión de roles en las que el vínculo deja de ser profesional para convertirse en amistoso o afectivo.

Este diagnóstico, como ya hemos mencionado, no expresará solo los déficits, sino que comprenderá también el conjunto de las capacidades, en especial las fértiles, entendiendo que es más eficaz intervenir desde lo que uno tiene que desde lo que se carece. Para ello, es posible utilizar indicadores cualitativos y no únicamente cuantitativos. 
Lo mismo se puede decir sobre el diseño de la intervención, y aquí no valen falsas apariencias contractuales. Si no hay diseño conjunto, no hay éxito. En este diseño se asignarán tareas y responsabilidades recíprocas. Ser ciudadano/a significa el reconocimiento de unos derechos, la exigencia de unas responsabilidades y la influencia en el funcionamiento de la sociedad, pasando de la indivisibilidad de la persona excluida a su presencia progresiva que nunca llegará a hacerse efectiva sin su protagonismo. Por ello debemos cuidar mucho este aspecto a la hora de diseñar y ejecutar nuestras intervenciones.

Otra idea que subyace en una relación profesional que busca incrementar las capacidades de las personas es la de flexibilidad. En la intervención social tenemos muchísima riqueza de contextos profesionales, muchos más que en otras profesiones. Así, la entrevista programada en un despacho, la visita a su domicilio, la presencia o al menos la coordinación activa con los proyectos donde hemos derivado a la persona, la atención adaptada a sus horarios, el encuentro casual en la calle, etc. Cada uno de ellos ofrece espacios, fines, momentos y duraciones diferentes: abiertos o cerrados, institucionales o personales, tiempos cortos o más largos, planificados o imprevistos, esporádicos o frecuentes. La intervención puede desarrollarse en una combinación de esos contextos, y la habilidad profesional consiste en utilizar todos según el matiz que se desee en ese momento. Los/as trabajadores/as sociales de servicios sociales se han acostumbrado a la comodidad de su despacho en horario de mañana (o de tarde) y parecen haber olvidado el trabajo en la calle, y sobre todo en los domicilios de las personas a las que atienden. Se ha apostado por una estandarización de la intervención en contra de una individualización de la misma.

Otro rasgo de la flexibilidad es la accesibilidad, fomentando todos los medios de comunicación disponibles para facilitar el contacto, en especial la utilización de las nuevas tecnologías.

Sintetizando, podríamos concluir que para poder fomentar la capacidad de agencia y por tanto de participación de la persona, el profesional debe adoptar una actitud de acompañamiento, entendido como proceso que fomente la comunicación y el diálogo. Es decir, supone situarse en un marco circular y sistémico de la persona, y no en términos de una prestación o servicio determinado. Se debe ofrecer más capacidad de relación y menos recursos económicos, resituando las esferas de poder en la relación para no seguir perpetuando los desequilibrios existentes en el vínculo constituido. Esta característica no significa que no se establezcan límites, tanto profesionales como los propios de la institución para la que se trabaja, ni que se tienda al conformismo estático amparado en la voluntad de la persona. Es más, es imprescindible establecer evaluaciones y balances como parte del proceso de responsabilidad de la persona y del cometido profesional. 


\section{BIBLIOGRAFÍA}

Arcarons, J., Raventós, D., y Torrens, LI. (2013): Una propuesta de financiación de una renta básica universal en plena crisis económica. Para garantizar la existencia material de toda la población. [Versión Web]. Recuperado el 19 de enero de 2014 desde http://www.sinpermiso.info/textos/index.php?id=6119.

Nussbaum, M.C. (2007). Las fronteras de la justicia. Barcelona: Editorial Paidós.

Nussbaum, M.C. (2012). Crear capacidades. Barcelona: Editorial Paidós.

Red Europea de Lucha Contra la Pobreza y la Exclusión Social en el Estado español (EAPN-ES) (2012). Guía metodológica de Participación Social de las personas en situación de pobreza y exclusión social. Madrid: EAPN Madrid.

Sen, A. (2000). Desarrollo y Libertad. Barcelona: Editorial Planeta.

Sen, A. (2010). La idea de la justicia. Madrid: Editorial Taurus.

Sen, A. (2011). Nuevo Examen de la Desigualdad. Madrid: Alianza Editorial.

Van Parijs, P., y Vanderborght, Y. (2006). La renta básica: una medida eficaz para luchar contra la pobreza. Barcelona: Editorial Paidós.

Wolff, J., \& De Shalit, A. (2007). Disadvantage. Oxford: Oxford University Press.

Young, I. M. (2000). La Justicia y la Política de la Diferencia. Madrid: Ediciones Cátedra. 